\title{
JERZY ZYBERT
}

Uniwersytet Warszawski

\section{Learning Anxiety in the Language Classroom}

ABSTRACT. It has generally been acknowledged that anxiety is an affective factor that plays a significant role in any learning. A highly specific type of anxiety, foreign language classroom learning anxiety, has been distinguished and recognised as quite common among foreign language learners (Horwitz et al. 1991). The article provides some theoretical considerations related to the issue and presents findings from research on it conducted among Polish secondary school students of English. Conclusions include some practical suggestions for language teachers.

\section{INTRODUCTION}

Foreign language learning processes are affected by a number of individual learner factors, both cognitive and affective. Anxiety, an important individual affective factor, is normally considered as a highly negative emotion that inhibits learning and which, in particular, is likely to suppress the learner's motivation for learning altogether. Language anxiety appears to bear a more detrimental than beneficial influence on learners' willingness to learn a language and, particularly, to speak it in the language classroom; therefore, this phenomenon should attract the special attention of language teachers. Anxiety is perceived as omnipresent in foreign language learning and, truly, it has attracted researchers' attention for quite some time (e.g., Maclntyre and Gardner 1989; Horwitz and Young 1991). Nevertheless, there is still some controversy concerning several issues, such as those about its relation to other individual differences (e.g. MacIntyre et al. 1997) or to the development of particular language skills (cf. Horwitz and Young 1991). Thus, a number of questions remain unresolved and further studies are needed to reach relevant generalisations. A better understanding of language anxiety, of its nature, sources, and role in language learning, espe- 
cially when related to classroom learning, may enable the language teacher to handle the learning problems pertaining to anxiety more adequately and to provide her with a knowledge to help students in their attempts to cope with the emotion; moreover, it should furnish her with wisdom on how to avoid creating anxiety-raising situations.

Anxiety is experienced bodily and its symptoms are clearly observable becoming dumb, sweating, shaky hands and voice, etc. First of all, however, it has a cognitive dimension as it affects the learner's thinking about the probability of negative outcomes that he attributes to anticipated and feared failures. There is substantial evidence to indicate that anxiety impedes the development of language skills, particularly that of speaking. Learning problems caused by anxiety are generally explained as resulting from its interference in processing input data. Anxiety also affects memorization, information retrieval, and generating language (cf. MacIntyre and Gardner 1991: 86). Moreover, high levels of language anxiety have an impact on such affective individual variables as self-esteem, self-confidence, and risk-taking (cf. Crookall and Oxford 1991). In his Affective Filter hypothesis, Krashen (1985) argues that anxiety raises the filter, thus effectively blocking learner access to input; high filter apparently hampers language acquisition in not allowing the conversion of input into intake. In this situation anxiety disables the learner's cognitive functions and prevents him from verbally demonstrating his actual language competence and abilities. A vicious circle then arises as the experienced failure not only evokes stress but also heightens the anxiety level in the learner.

Psychological research demonstrates that cognitive processes depend largely on the individual's emotions that inherently accompany any learning. The current affective state of a student normally determines both his attitudes towards the learning environment and his feelings of well-being within the environment. A foreign language lesson is a real event that takes place in a certain physical environment. The student's involvement in the language learning process and his ability to focus attention on classroom tasks and activities depend, among other things, on whether or not he feels safe and free from stress in the environment. From this it follows that language anxiety is an individual learner problem. The difficulties experienced by him in attempts to express intended meanings (i.e., lack of available linguistic resources) often do not allow him to behave naturally. Awareness of gaps in competence can even paralyze him and cause a feeling of guilt. In consequence, anxiety leads to lowering one's self-assessment, reduces confidence about one's intellectual potential, and deprives one of assertiveness.

In spite of the obvious significance of the anxiety issue, a great number of language teachers do not seem to be aware of its seriousness. It is hoped, however, that raising their consciousness concerning its harmfulness for 
language learning will result in their greater care about eliminating anxiety from the classroom. The first step in doing so is proper understanding of the issue.

\section{THE CONCEPT OF ANXIETY}

First of all, it is important to bear in mind that not all anxiety relates to language learning and that when it does it can also be somewhat beneficial for learning. Still, anxiety is rather difficult to define. In the most general terms, anxiety is seen as a psychic discomfort experienced by an individual. Because of this emotion the learner's actual learning potential and abilities to perform learning tasks are perceived by him as markedly lower than they really are. The sensed insecurity incites a fear of failure, of not being up to the situation, thus making even simple things seem highly complex and difficult. A student who experiences anxiety feels threatened, he may be overwhelmed with irrational fear and worry in the face of what is new and unknown; all this develops internal tension in him. Therefore, anxiety introduces an individual into a static state, whereby the mind freezes (metaphorically, though) and the body becomes motionless. Such a state is reflected in everyday language, when one says that fear paralyzes someone's tongue or legs.

Definitions of anxiety offered by psychologists may differ from one another but they usually capture the idea of the individual's strong feelings of apprehension, uneasiness, embarrassment and awkwardness. For instance, Zimbardo (1985) defines it as "an intense emotional response caused by the preconscious recognition that a repressed conflict is about to emerge into consciousness" (p. 111). Anxiety affects the individual emotionally making him experience nervousness, tension, or even fear that is related to a relevant object, situation, or circumstance.

Considering anxiety in relation to foreign language learning, a distinction must be made between the so called trait anxiety, which is defined as "a more permanent predisposition to be anxious" (Scovel 1978, in Ellis 1994: 479) from the anxiety that pertains only and specifically to foreign language learning situations. Trait anxiety can be a characteristic of a given human being and, actually, may be inherent, to a greater or lesser degree, in some learners. It is a stable personality factor and is typical of neurotic individuals; as such, it is of little relevance to language learning. On the other hand, situational anxiety is that kind of anxiety that is produced or stimulated by various situations and circumstances and can be experienced by everyone. However, if anxiety is aroused exclusively in/by the specific situation of foreign language learning it is called foreign language anxiety or, perhaps 
better, language learning anxiety. Truly, lots of people are subjected to the feelings of discomfort, insecurity, and uncertainty in language learning situations, no matter how self-assured they may be.

Anxiety is very common among all people and, as has already been noticed, is generally and typically experienced negatively. Paradoxically, however, it is worth noting that anxiety can also be desired. According to the Yerkes-Dodson law a certain amount of anxiety can be useful in some cases ${ }^{1}$. A dose of anxiety seems even necessary to achieve success in learning; for example, without any fear about the possibly unsatisfactory results of learning, the student may not be aware of a potential danger of failure. Thus, an anxiety that acts as an alerting signal can stimulate the learner to undertake due action, that is, work harder. The level of anxiety may, of course, be different in individual learners and it is also conditioned by the difficulty level of the learning task - the more difficult it is, the higher the anxiety level (Fontana 1988: 131). In consequence, two additional labels are used in order to distinguish between kinds of anxiety: facilitating anxiety and debilitating anxiety.

\section{ANXIETY IN FOREIGN LANGUAGE LEARNING}

As mentioned above situational anxiety is directly relevant to foreign language learning. Foreign language classroom anxiety was first considered as a separate and distinct emotion by Horwitz et al. (1986). They pointed out that it occurs characteristically in the language classroom in reaction to everything that takes place in it and in connection with it. The very unique language learning situation generated by the specificity of foreign language learning and its use is described as a specific, subjectively intuited and experienced internal strain, apprehension, worry, and nervousness linked with the autonomic nervous system. The state combining such feelings is most often induced in the learner by situations in which he is required to speak the foreign language in the presence of others (cf. Horwitz et al., ibid. p. 27). In the language classroom it can result in a sort of mental panic when the student is made to speak despite his currently inadequate competence and little practice to cope with the teacher's demands. In attempts to satisfy the teacher's expectations he will often produce very odd and improper forms in response to the teacher's utterances (cf. excellent authentic examples provided by Felix 1982, cited in Allwright and Bailey 1991: 146). It is also assumed that language anxiety affects the learner's self-esteem and the ability

1 "Performance is enhanced with mild levels of anxiety but begins to suffer if the anxiety becomes too great (MacLeod 1998: 548)". 
to take risks (Brown 2000). The feeling of psychic discomfort and embarrassment stems from the learner's realized inability to express the intended meanings verbally, which he attributes, consciously, to the gaps in his communicative FL competence. This, in turn, produces further unwelcome feelings, such as helplessness and vulnerability. All in all, exposure to public opinion engenders anxiety. The sensitive, non-assertive learner chooses to avoid unpleasant situations; in order to save face he prefers maintaining silence to taking any risk and speaking in public, i.e., before classmates and the teacher. This, obviously, deprives him of language learning opportunities and demotivates from language learning.

Admittedly, language anxiety occurs among a significant number of students ${ }^{2}$, especially while they attempt to communicate in the foreign language during language lessons. Students themselves admit that they become worried and frustrated in these situations even though they normally do not feel so in their everyday lives.

From the above it follows that language anxiety is a phenomenon which is not only very common among language learners but also very complex; neither is it necessarily connected with simple nervousness or ordinary fright. Consequently, language anxiety is understood as "a distinct complex of self-perceptions, beliefs, feelings, and behaviors related to classroom language learning arising from the uniqueness of the language learning process" (Horwitz et al. 1991: 31). A similar definition is offered by Gardner and MacIntyre (1993) according to whom "Language anxiety is fear or apprehension occurring when a learner is expected to perform in the second or foreign language" (cited after Oxford 1999: 59). A number of other definitions have been advanced (cf., e.g., Scovel 1978; Heron 1989; Price 1991; Daly 1991). Although they differ in detail, they have one feature in common: they all relate the phenomenon of language anxiety to using a foreign language, particularly when it is requested or expected of them or when they themselves feel obliged to do so in the presence of other people. The claim about the very "uniqueness of the language learning process" is undeniably true and, consequently, language learning must not be compared with other school subjects, especially in terms of the kind of anxiety that language learning produces. According to MacIntyre and Gardner (1991a) language anxiety is distinct from other types of anxiety due to cognitive interference into the learning process. Apart from concentrating on doing a task, learners also pay attention to their emotions and performance. This is why anxious learners are likely to evaluate themselves negatively and worry about their achievements, which impairs their actual performance in the language that they are learning.

2 It is estimated that about a half of all students in an average class experience language anxiety (Campbell, Ortiz 1991). 


\section{CAUSES OF FOREIGN LANGUAGE ANXIETY}

A number of variables and situations contribute to the students' feelings of nervousness during language classes. It is claimed, for example, that it is aroused by the learner's apprehension that his self-esteem and his image in the eyes of the teacher and classmates will be threatened because of the perceived limited linguistic means (cf. Horwitz et al., op.cit.). Identification of anxiety-producing factors provides ground for distinguishing certain specific categories of classroom language learning anxiety. For the sake of brevity in this article, we look briefly only at the most noticeable ones which include: communication apprehension, fear of negative evaluation, social/interpersonal anxiety, and student's beliefs about language learning.

Communication apprehension relates to learners' unwillingness or even resistance to speaking in a foreign language. It is defined as "a type of shyness characterized by fear or anxiety about communicating with other people. Difficulty in speaking in dyads or groups (oral communication anxiety) or in public ('stage fright'), or in listening to or learning a spoken message (receiver anxiety) are all manifestations of communication apprehension" (Horwitz et al., op.cit., p. 30). Even if people are able to form thoughts and ideas perfectly, language learners are frequently unable to express them properly, which gives rise to frustration or even anger. What further aggravates the anxiety is the feeling of helplessness and the awareness of the stigmatizing power of errors that they can make in pronunciation and vocabulary use.

Learners' ability to communicate in a foreign language can be affected by several factors. One of them is the awareness of being monitored and evaluated by the teacher - this diverts attention from message content. It also explains why most learners, especially at lower levels of proficiency, prefer pair or group work - they feel more at ease when the judgment element does not accompany a speaking task (Daly 1991:9). Classroom anxiety can also be aroused by ambiguity, which stems from learners' uncertainty about the teacher's criteria for evaluating them or of his further steps; it is also induced by ambiguous new vocabulary and unfamiliarity with social norms for language use (ibid., p. 10). Conspicuousness is a further anxiety-producing factor; in fact, in some cases it is desired, e.g., by public celebrities like artists or politicians, but to most ordinary people being exposed to the attention of others is embarrassing. "People generally prefer not to be the focus of attention especially when they feel they are engaging in an activity where their competence is low" (ibid.). The concomitant stress results from the fear of appearing incompetent and of being laughed at by other students (Price 1991: 105). Also, prior history may decide about anxiety: earlier negative experience may evoke a fearful attitude toward a subsequent communicative event (Daly, op. cit., p. 10).

Students are normally sensitive about being evaluated by both their teachers and classmates. Expectation of negative evaluation, whether rational or not, is 
another serious source of anxiety - it stems from fear that unfavourable assessment may damage the student's image and, thus, have adverse social consequences. Fear of negative evaluation, which subsumes test anxiety, is particularly acute when learners anticipate that a negative opinion becomes known to others (including their poor test results). Evaluation is also strictly connected with errors made by students - a tactless way of correcting them ${ }^{3}$ (humiliating, especially if done in front of other students) is a very serious source of anxiety.

A relatively strong source of classroom language anxiety is the student's perception of himself as a learner in relation to other students in the same class; the resulting kind of anxiety is often labelled social/interpersonal anxiety. Individual students are often inclined to consider the rest of their group as a background against which they compare their own performance and achievement. Those whose subjective judgment is to their disfavour perceive themselves as inferior - they, in reality, are not necessarily much worse learners but the very unsatisfactory comparison produces their anxiety. Comparison with others frequently lowers self-esteem and develops into competitiveness. Its effects can be positive when an individual manages to surpass those he compares himself with; however, when the invested effort turns out to be futile, then anxiety will grow to the detriment of learning. Apart from competitiveness, social/interpersonal anxiety is often generated in learners by the environment that includes the teacher, parents, and others who exert pressure on learners for high achievement. Social expectations often exceed the student's learning potential - this kind of pressure certainly evokes and increases debilitating anxiety.

Students' beliefs about language learning constitute another source of foreign language learning anxiety. Learners may believe, for example, that language learning must necessarily involve developing perfect pronunciation, or mastering all grammar rules, or that native-like competence can be achieved effortlessly and in an irrationally short time. Beliefs like these and many others are often unrealistic and when they do not coincide with classroom teaching practices and learning experiences, the clash between expectations and harsh reality will produce anxiety (cf. Young 1991).

\section{INVESTIGATING CLASSROOM LANGUAGE LEARNING ANXIETY}

Claims have also been advanced that foreign language anxiety is actually never present at the very start of a student's language learning experience, but develops in the course of learning it (cf. MacIntyre and Gardner 1991b). The cases of tenseness that some students feel in the classroom at this initial

${ }^{3}$ Unfortunately, quite a number of teachers interrupt students' oral productions to indicate and/or correct their errors. 
phase of language learning are attributed to either trait anxiety or general communication apprehension. The initial stress can also be due to the very novelty of the foreign language learning situation. It is argued that it should soon vanish after the student gets used to the peculiarities of the situation, becomes familiar with the teacher, peers, types of classroom activity, etc. (cf. Daly, op.cit., p. 10). However, the new learning situation may induce and develop language learning anxiety. "As negative experiences persist, foreign language anxiety may become a regular occurrence and the student begins to expect to be nervous and to perform poorly" (MacIntyre and Gardner 1991b., p. 110). This evidently indicates that classroom language learning anxiety need not accompany language learning if due care about creating a friendly atmosphere in the classroom is taken by the teacher.

However, this line of thinking does not always seem to be reflected in reality - both teachers and students admit that language anxiety is not only very common in language classes, but that it also occurs at the initial stages of language learning at school. In order to arrive at a picture of actual occurrence of anxiety in the Polish language classroom and to consider its role in foreign language learning among secondary school students we have carried out some related research ${ }^{4}$. In general terms, its main objectives were to find out how students experience and perceive the presence of anxiety in foreign language learning and how they define its influence on their own language learning; moreover, we were also interested in whether and how students cope with the anxiety that they experience. More specifically, the research aimed to define:

i) actual commonness of anxiety aroused in the language classroom,

ii) sources of language anxiety,

iii) symptoms of anxiety experienced by students,

iv) extent of awareness of experienced anxiety,

v) students' own actions against anxiety,

iv) their expectations of obtaining help in fighting anxiety.

The subjects selected for the investigation were 187 lower secondary school students of English (3rd graders), both male and female, aged 15-16, considered pre-intermediate. The instrument used for the research was a questionnaire specially designed for the purpose of this article (see Appendix). It focused on the subjects' emotions, convictions, and experience related to language learning anxiety and consisted of ten questions.

- the first question concerned the learner's general attitude toward learning a foreign language; attitude can be indicative of emotional states; it was assumed that attending language classes with pleasure lowers the affective filter;

${ }^{4}$ Not all factors discussed above were investigated - this would exceed the intended scope and size of a journal article. 
- answers to the second question were expected to show how common language learning anxiety is among students, what proportion of all students undergo anxiety;

- the third question attempted to estimate the level of anxiety experienced by the subjects;

- the fourth question aimed to identify the sources of their anxiety;

- the fifth question asked students to describe the symptoms of their anxiety;

- the sixth questions was intended to find out how students cope with anxiety - undertake action to reduce/eliminate anxiety or not;

- the seventh question was intended to identify the possible ways of coping with anxiety;

- the eighth question meant to elicit learners' preferences for resolving the anxiety problem;

- the ninth question was about the learner's opinion concerning the role and influence of anxiety on language learning; whether anxiety can be a possible excuse for failure;

- the tenth question invited students to provide examples, comments, remarks related to learning anxiety..

\section{FINDINGS}

a. Closed-ended questions

Question 1. Students' attitude toward language lessons at school pleasure $=32(17 \%) \quad$ indifference $=138(74 \%) \quad$ discontent $=17(9 \%)$

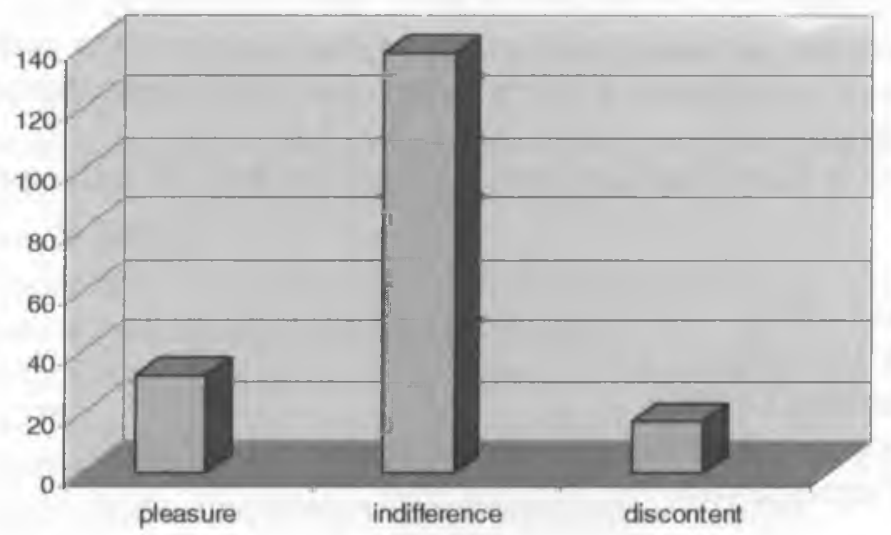


Less than a fifth of the subjects experience language classes as a pleasure; the majority are indifferent and less than a tenth express discontent. It can be assumed that the figures provide a rather negative picture of the subjects' interest/involvement in foreign language learning. This is disappointing in the light of the obligatory end-of-school foreign language examination (Cf. the last finding in question 4 below).

Question 2. Anxiety experienced / not experienced in language lessons

$$
\text { Yes }=50(27 \%) \quad \text { No }=137(73 \%)
$$

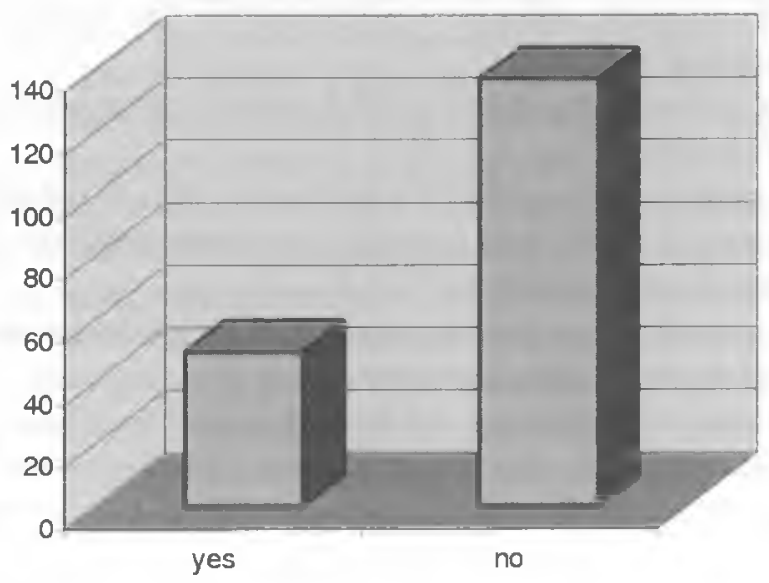

Among those who experience anxiety are students included in all the three categories distinguished in question 1 above. Interestingly, anxiety is experienced even by students who like their language classes -7 of them admit they do. On the other hand, not surprisingly, all 17 students who do not like language classes experience anxiety; the remaining 26 students who experience anxiety admit an indifferent attitude to language classes.

Question 3. Individual assessment of anxiety level on a five-point Likertlike scale

1) slight $4=8 \%$;

2) weak $17=35 \%$;

3) moderate $22=43 \%$;

4) quite strong $4=8 \%$;

5) very strong $3=6 \%$ 


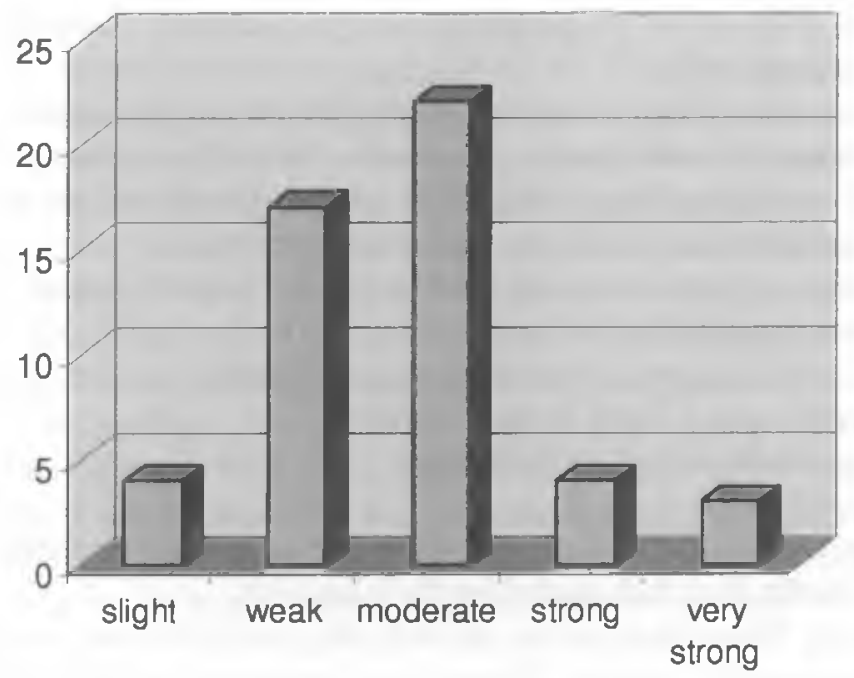

Question 4. Students' belief that they would learn English better if they did not experience feelings like those mentioned in question 2

$$
\text { Yes }=100 \% \quad \text { No }=0 \%
$$

All students are convinced that their anxiety affects language learning negatively. This finding supports the claim about the detrimental influence of anxiety on language learning and of learners' awareness of it.

b. Open-ended questions

Question 4. The most common causes of classroom language learning anxiety are as follows:

- Obligation to speak English to whole class (I get nervous/tense when everybody is listening to me speaking English) $=42(84 \%)$.

- Responding to the teacher in English (she forces me to answer in English) $=38(76 \%)$.

- Expressing intended meanings (I cannot say what I want in English) = $36(72 \%)$.

- Tests $=31(62 \%)$.

- Apprehension about form (I know I make lots of errors) = $31(62 \%)$.

- I am not fluent (speak haltingly) $=24(48 \%)$.

- Incomprehensibility (I do not understand what the teacher says to me) $=11(22 \%)$.

- My English results may determine that I will not get into a good higher education institution (they will not want me) $=5(10 \%)$. 
Question 5. How do you experience it? How does it manifest itself (internally or externally)?

- I feel insecure when I must speak English in the classroom

- I feel nervous when I expect a question from the teacher

- I am afraid of making errors when speaking in the classroom $24(48 \%)$

- I am embarrassed when the teacher corrects me

- I become nervous when the teacher speaks English to me

- I am always afraid of tests

- I am afraid I cannot understand spoken English

$14(28 \%)$

- My heart beats / I feel dizzy / I blush

- I feel generally tense, embarrassed

- I get hot; I sweat

The above quotations from the respondents' questionnaires suggest that it is fear of losing face that underlies their anxiety.

Question 6. No answers were given to the question what learners do/how they try to overcome anxiety. This shows that students feel helpless and also that teachers are unaware of the problem and/or unable to help students.

Question 7. Total lack of answers is a logical consequence of the above.

Question 8. In students' opinion the best ways of eliminating anxiety in the classroom is collaborative work and using L1:

- Pair work and small-group work activities $=38(76 \%)$

- Doing homework with friends (to prepare for classroom tasks) $=31$ $(63 \%)$

- Permission to use Polish (L1) in lessons, translating = $18(36 \%)$

The scanty suggestions given by students display their helplessness in the face of anxiety.

Question 9. All students who admit that they experience anxiety claim that they would do better if they did not experience anxiety, which again means they are powerless, frustrated and need help. Surprisingly, a significant number $(56=41 \%)$ of those who answered "no" to question 2 also made the same claim.

Question 10 was an invitation to express individual views on the issue of anxiety

This item was filled in by both groups of subjects: those who admitted experiencing anxiety $(31=62 \%)$ and those who did not $(71=52 \%)$.

\section{FINAL COMMENTS AND CONCLUSIONS}

Students' answers to the questions posed in the questionnaire allow some conclusions to be drawn. Firstly, it turns out that more than a quarter of the learners (27\%) admitted they experience anxiety. This is a significant figure, which corroborates the claim about the commonness of the anxiety 
factor in classroom foreign language learning. In consequence, it calls for teachers' close attention to the seriousness of the problem, the more so that it occurs not only among students who do not find any pleasure in language learning but also among those who find it pleasurable. Secondly, the most common reasons for anxiety, as reported in the questionnaires, should draw teachers' particular attention to their dealing with the class as potentially engendering anxiety. A further, highly significant finding is that many students are evidently not aware of their anxiety. The finding that the students who claim that they do not experience anxiety (cf. question 2) did, nevertheless, respond to questions 9 and 10 (cf. the results above) shows that they themselves do experience anxiety, but are not aware of it. Their answers (questions 2 vs. 9 and 10) stand in their mutual downright contradiction! The general conclusion drawn from their comments is that these students are not satisfied with their low achievement and poor performance in the classroom; nevertheless, they put the blame for it on the feelings that evidently stem from their anxiety. ("I could do better if I were more relaxed in the language class; were not afraid to make mistakes"; etc.)

Additionally, it is worth noting that anxiety may be engendered in the classroom by competitive situations. Individual discussions with highly anxious learners reveal that they feel discriminated against because teachers constantly praise and give preference to some pupils, their favourites, at the expense of the poorer students. The latter compare themselves with the better ones and are, thus, worried that they are perceived by both teachers and other learners as inferior. On the other hand, good learners also admit that they are susceptible to anxiety in some specific situations. This is explained by teachers: they report that low achievers often provoke unhealthy situations by exerting pressure on high achievers not to exhibit their language skills and abilities (in fact, their superiority) - these students become terrified (bullied or intimidated); anxiety thus induced hampers their performance in the classroom.

All in all, what emerges from the results presented above is that teachers should carefully control both their own behaviour and that of all students; it is also imperative that they take care to create a learning environment that is friendly, that enhances personal security and minimizes anxiety.

\section{APPENDIX}

\section{What stresses you in the language class?}

1. Do you like language lessons at school? $P u t X$ in the appropriate box Yes (:) Neither $\odot$ No 2 
2. Do you experience feelings such as anxiety, nervousness, fear, and the like during language classes? Underline the appropriate answer

Yes No

3. If you do, try to assess their strength on a 5-point scale - indicate your judgement 1 = slight $\quad 2$ = weak $\quad 3=$ moderate $\quad 4$ = quite strong $\quad 5$ = very strong

4. What generates such feelings in you? What makes you nervous? Try to explain briefly

5. How do you experience them? How does anxiety manifest itself (internally or externally)? Provide a brief description

6. If you experience these feelings, do you try to overcome them? Underline the appropriate answer

Yes No

7. If your answer above is "yes", how do you do it? Provide a brief description

8. What, in your opinion, is a good remedy for such feelings? Provide a brief answer/suggestion(s)

9. Do you think that you would learn English better if you did not experience such feelings as those mentioned in 2 ? Underline the appropriate answer

Yes No

10. If you wish to provide examples, comments, remarks concerning the issue examined in this questionnaire, you can do it here and continue overleaf

\section{Thank you}

Stevick 1976: "lathophobic aphasia" - "unwillingness to speak for fear of making a mistake"

\section{REFERENCES}

Arnold, Jane (ed.), 1999. Affect in Language Learning. Cambridge: Cambridge University Press.

Crookall, David / Rebecca Oxford, 1991. "Dealing with Anxiety: Some Practical Activities for Language Learners and Teacher Trainers". In: Horwitz Elaine K. / Young Dolly J. (eds.), 141-150. 
Daly, John, 1991. Understanding Communication Apprehension: An Introduction for Language Educators. In: Horwitz Elaine K. / Young Dolly J. (eds.): 3-13.

Eysenck, Michael (ed.) 1998. Psychology - an integrated approach. Harlow: Longman.

Heron, J., 1989. The Facilitator's Handbook. London: Kogan Page.

Horwitz, Elaine K / Dolly J. Young (eds.), 1991. Language Anxiety. From Theory and Research to Classroom Implications. Englewood Cliffs, NJ: Prentice Hall.

Horwitz, Elaine K. / Michael B. Horwitz / Jo A. Cope, 1991. Foreign Language Learning Anxiety. In: Horwitz E.- J. Young D. (eds.): 27-36.

Macintyre, Peter D. / Robert C. Gardner, 1989. Anxiety and second language learning - toward a theoretical clarification. In: Language Learning, Vol. 39: 251-275.

MacIntyre, Peter D. / Robert C. Gardner, 1991a. Investigating language class anxiety using the focused essay technique. In: The Modern Language Journal, Vol. 75, No. 3: 296-304.

MacIntyre, Peter D. / Robert C. Gardner, 1991b. Methods and results in the study of anxiety and language learning: a review of the literature. Language Learning, Vol. 41: 85-117.

Maclntyre, Peter D. / K. Noels / R. Clément. 1997. "Biases in self-ratings of second language proficiency - the role of language anxiety". In: Language Learning, Vol. 47: 265-287.

MacLeod, Andrew, 1998. Abnormal psychology. In: Eysenck Michael (ed.): 532-562.

Oxford, Rebecca L. 1999. Anxiety and the language learner: new insights. In: Jane Arnold (ed.), 58-67.

Price, Mary L., 1991. The Subjective Experience of Foreign Language Anxiety; Interviews with Highly Anxious Students. In: Horwitz E. K. / Young D. J. (eds.): 101-108.

Scovel, Thomas, 1991. The Effect of Affect on Foreign Language Learning: A Review of the Anxiety Research. In: Horwitz E. K. / Young D. J. (eds.), 15-23.

Young, Dolly, J., 1991. Creating a Low-Anxiety Classroom Environment: What Does Language Anxiety Research Suggest? In: The Modern Language Journal, Vol. 75, No. 4: 426-439.

Zimbardo, Philip G., 1985. Psychology and Life. London: Harper Collins Publisher. 